\title{
BMJ Open Early impact of the COVID-19 pandemic on in-person outpatient care utilisation: a rapid review
}

\author{
Julien Dupraz (D) , Marie-Annick Le Pogam, Isabelle Peytremann-Bridevaux
}

To cite: Dupraz J, Le Pogam MA, Peytremann-Bridevaux I. Early impact of the COVID-19 pandemic on in-person outpatient care utilisation: a rapid review. BMJ Open 2022;12:e056086. doi:10.1136/ bmjopen-2021-056086

- Prepublication history and additional supplemental material for this paper are available online. To view these files, please visit the journal online (http://dx.doi.org/10.1136/ bmjopen-2021-056086).

Received 02 August 2021 Accepted 18 January 2022

Check for updates

(C) Author(s) (or their employer(s)) 2022. Re-use permitted under CC BY-NC. No commercial re-use. See rights and permissions. Published by BMJ.

Center for Primary Care and Public Health (Unisanté), University of Lausanne, Lausanne, Switzerland

Correspondence to Dr Julien Dupraz; julien.dupraz@unisante.ch

\section{ABSTRACT}

Objectives To quantitatively assess the early impact of the COVID-19 pandemic on in-person outpatient care utilisation worldwide, as well as across categories of services, types of care and medical specialties.

Design Rapid review.

Method A search of MEDLINE and Embase was conducted to identify studies published from 1 January 2020 to 12 February 2021, which quantitatively reported the impact of the COVID-19 pandemic on the amount of outpatient care services delivered (in-person visits, diagnostic/screening procedures and treatments). There was no restriction on the type of medical care (emergency/primary/specialty care) or target population (adult/paediatric). All articles presenting primary data from studies reporting on outpatient care utilisation were included. Studies describing conditions requiring hospitalisation or limited to telehealth services were excluded.

Results A total of 517 articles reporting 1011 outpatient care utilisation measures in 49 countries worldwide were eligible for inclusion. Of those, $93 \%$ focused on the first semester of 2020 (January to June). The reported results showed an almost universal decline in in-person outpatient care utilisation, with a $56 \%$ overall median relative decrease. Heterogeneity across countries was high, with median decreases ranging from $10 \%$ to $91 \%$. Diagnostic and screening procedures (-63\%), as well as in-person visits $(-56 \%)$, were more affected than treatments $(-36 \%)$. Emergency care showed a smaller relative decline $(-49 \%)$ than primary $(-60 \%)$ and specialty care $(-58 \%)$ Conclusions The provision of in-person outpatient care services has been strongly impacted by the COVID-19 pandemic, but heterogeneously across countries. The longterm population health consequences of the disruption of outpatient care service delivery remain currently unknown and need to be studied.

PROSPERO registration number CRD42021237366.

\section{INTRODUCTION}

The COVID-19 pandemic has had a major impact on health systems worldwide and is still disrupting health services in many countries. ${ }^{1}$ While much attention has been paid to the acute care of patients with COVID-19 and public health mitigation measures, research focusing on the impact of the pandemic on non-COVID-19-related care has only recently

\section{Strengths and limitations of this study}

This study is a comprehensive review of the early impact of the COVID-19 pandemic on in-person outpatient care utilisation worldwide.

- Despite an almost universal decline in outpatient care utilisation, we were able to show a high heterogeneity across countries and types of care.

- The validity of estimates provided for some countries or specialties could be limited by the small number of observations.

received attention. ${ }^{2}$ Reductions in the utilisation of non-COVID-19 acute hospital and outpatient care services have been reported worldwide. $^{3}$ These have resulted from government closure of elective care services during lockdowns and reduced patient demand due to fear of infection while visiting a care facility. Consequently, concerns have emerged about the risk such disruptions may represent both to patients suffering from acute nonCOVID-19 diseases requiring hospital care and those with chronic conditions such as diabetes, chronic respiratory diseases and cancer. $^{45}$

A better understanding of the magnitude of outpatient care utilisation changes during the COVID-19 pandemic would help to anticipate its medium-term and long-term consequences. Although several authors have reported on the quantitative impact of the pandemic on outpatient care provision at the level of a region or a specific type of care or disease, attempts of evidence synthesis are scarce and often limited in their scope. ${ }^{6-8}$

The primary objective of this rapid review was to summarise the early impact of the COVID-19 pandemic on in-person outpatient care utilisation worldwide, as well as across categories of services, types of care and medical specialties. 


\section{METHODS}

The study followed the guidance of the Cochrane Rapid Reviews Methods Group 9 and was registered on PROSPERO (CRD42021237366). Our abstract and review are reported according to the Preferred Reporting Items for Systematic Reviews and Meta-Analyses statements. ${ }^{10}$

\section{Search strategy and study eligibility}

We performed a search of the MEDLINE and Embase databases for articles published between 1 January 2020 and 12 February 2021, to identify studies reporting primary quantitative data on the impact of the COVID-19 pandemic on the amount of outpatient care services delivered, without restriction on the type of care (emergency, primary or specialty care) or target population (adult or paediatric). An experienced librarian drafted the search strategy; the full search strategy is provided in the online supplemental table S1. We excluded articles not reporting quantitative results, dealing only with telehealth services or focusing on conditions requiring hospitalisation like myocardial infarction or stroke.

\section{Identification of studies}

In the screening step, one author (JD) examined the titles and abstracts to exclude out-of-scope articles. In the eligibility step, one author (JD) retrieved the full texts of potentially relevant articles to assess their eligibility. The reference lists of available reviews on the topic were also handsearched to identify other relevant studies.

\section{Data extraction}

For each included article, one author (JD) extracted the following information using an extraction grid: year of publication (the earliest if published online first); country; data source (administrative health data, survey, insurance claims data or other); service provider characteristics (individual healthcare professional or organisation, as opposed to multiple; for multiple providers, the geographic distribution was further characterised as local, national or international); target population (adult, paediatric, both or unknown); COVID-19 period and period of reference (to which the COVID-19 period was compared, when available). In studies distinguishing several time intervals during the COVID-19 period, the one with the most substantial impact of the pandemic on outpatient care utilisation was retained. When several reference periods were available, we favoured (in order of preference): (1) dates in 2019 corresponding to the COVID-19 period; (2) the prelockdown period and (3) any other period of reference.

We identified all available measures of outpatient care utilisation within included articles, defined as a quantitative assessment of the impact of the COVID-19 pandemic on the use of an outpatient care service. In articles reporting the impact on several outpatient care services, every distinct measure was considered. Each measure reported was categorised into one of the three following categories of services: treatment (ie, all therapeutic interventions, like surgical procedures, chemotherapy sessions, psychotherapy sessions, dialysis, etc), diagnostic/ screening procedure (ie, all non-therapeutic procedures, like diagnostic imaging, echocardiography, biopsy, etc) or in-person visit (ie, all visits not falling into the aforementioned categories). We also extracted the following information: type of care (emergency care, non-emergent primary care, non-emergent specialty care, screening, or mixed); medical specialty; specific service considered (eg, in-person visit, echocardiography, chemotherapy session); unit of measurement (eg, absolute number, mean, rate, relative reduction or increase) and the quantitative estimate. When available, we extracted absolute estimates rather than relative ones. To derive a relative impact (percentage of increase or decrease) from absolute estimates, we used the following formula: (absolute estimate during COVID-19 period-absolute estimate during reference period)/absolute estimate during reference period. We contacted the corresponding authors of studies providing incomplete results (eg, graphs lacking exact estimates) to obtain complementary information, where relevant. Given the many studies included and their nature (mostly short reports with limited methodologic information), we did not assess the risk of bias.

\section{Statistical analysis}

We performed simple descriptive statistics to characterise the articles included. We considered estimates of the relative impact of the COVID-19 pandemic on the use of a specific service (extracted or calculated) together to compute the median relative impact and IQR according to several dimensions (country, category of service, type of care, specialty). Measures not allowing the estimation of a relative impact were treated separately. Statistical analyses were performed using Stata/IC V.16.1.

\section{Patient and public involvement}

There was no participation of patients or the public in the design or conduct of this study.

\section{RESULTS}

A total of 4492 records were identified; of those, 629 fulltext articles were retained for eligibility assessment after screening of titles and abstracts (figure 1). After exclusion of 112 articles, mainly because they did not report quantitative results (online supplemental table S2), 517 studies were included in the review. Study characteristics are presented in table 1 and studies are listed in online supplemental table S3. Articles were primarily based on administrative health data $(72.3 \%)$ or surveys $(20.5 \%)$. Approximately one-half of the articles involved a single healthcare professional or organisation $(53.8 \%)$, while the remainder reported results on multiple providers within a country $(38.5 \%)$ or in several countries $(7.7 \%)$. A few articles were explicitly dedicated to the paediatric population (13.9\%). Most articles were published in 2020 $(87.0 \%)$ and almost all focused on the first semester of 


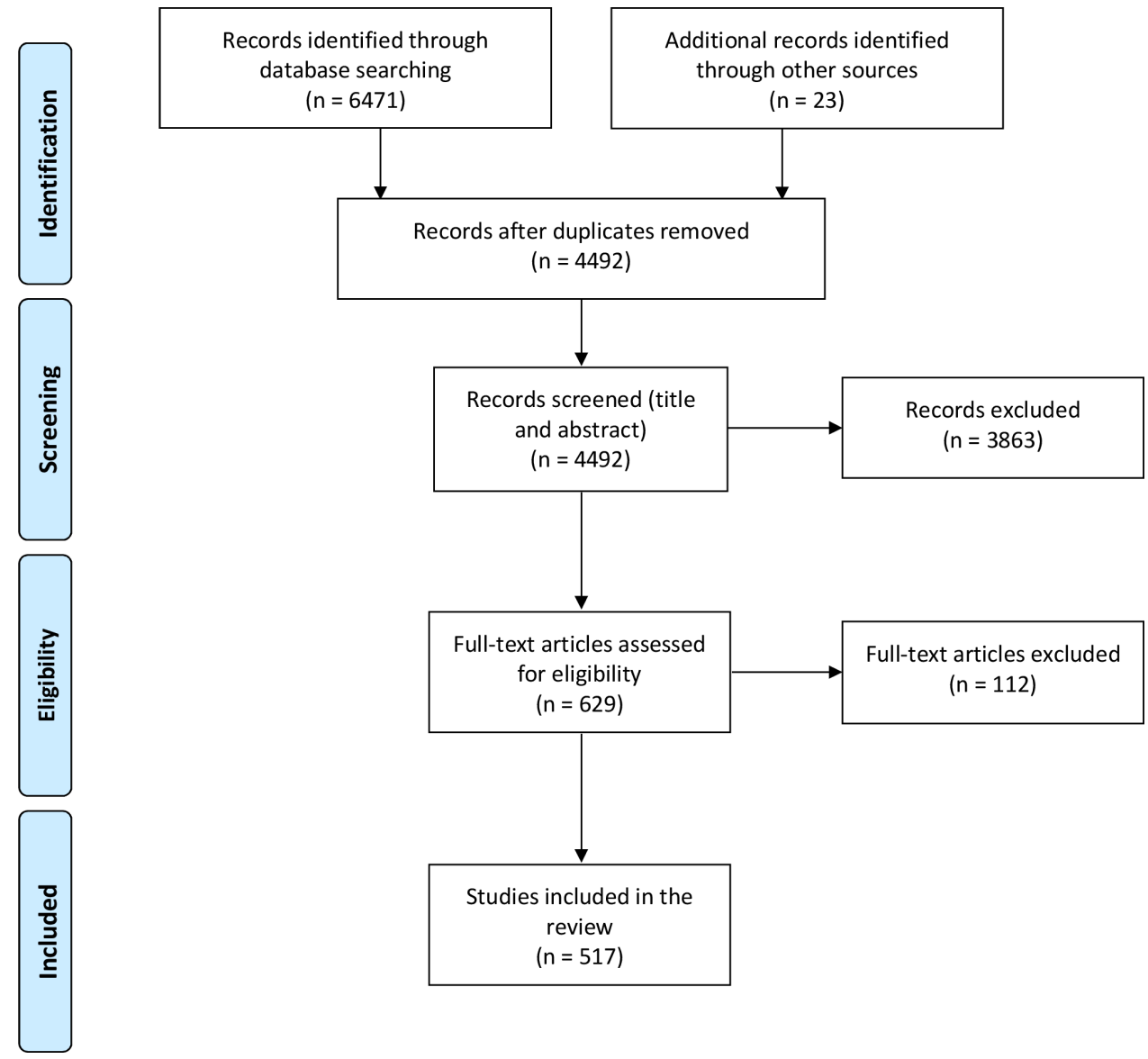

Figure 1 Preferred Reporting Items for Systematic Reviews and Meta-Analyses flow diagram.

2020 (January to June, 93.4\%). In the majority of cases, the reference period was the corresponding period in $2019(53.0 \%)$ or the prelockdown period (21.3\%). Overall, we identified 1011 measures of the impact of the COVID-19 pandemic on the use of specific outpatient care services. The number of measures by article ranged from 1 to 12, for an average of 1.96 (SD 1.88). Articles covered 49 different countries worldwide (table 2). The USA $(n=106)$, Italy $(n=96)$ and the UK $(n=40)$ provided the greatest number of articles.

\section{Relative impact of the COVID-19 pandemic on in-person outpatient care utilisation}

Among the 1011 identified measures, 858 (84.9\%) provided an estimation of the relative impact (percentage of increase or decrease) of the COVID-19 pandemic on service use or allowed its calculation. Most of these estimates concerned in-person visits $(61.4 \%)$, followed by diagnostic and screening procedures $(23.3 \%)$ and treatments $(15.3 \%)$. Regarding their distribution among types of care, most relative impact estimates related to specialty $(57.0 \%)$ and emergency care $(36.6 \%)$. Primary care $(2.7 \%)$, screening $(1.6 \%)$ and mixed types of care $(2.1 \%)$ were much less represented.

Overall, when considering all countries, categories of services and types of care, the reported results showed a 55.5\% median decline in in-person outpatient care utilisation (IQR 34.6\%-74.0\%). Heterogeneity across countries was high, with median outpatient care utilisation decreases ranging from $10.3 \%$ to $90.9 \%$ (figure 2, table 2); Iceland was the only exception, showing a $16.4 \%$ increase in outpatient care utilisation. Median decline for categories of services was $62.9 \%$ in diagnostic and screening procedures (IQR 46.3\%-80.1\%), 56.2\% in in-person visits (IQR $35.2 \%-73.7 \%$ ) and $36.1 \%$ in treatments (IQR 12.4\%-56.1\%). Regarding types of care, there was a $76.4 \%$ median decrease in screening (IQR $56.3 \%-84.8 \%$ ), $59.9 \%$ in primary care (IQR 22.6\%$70.6 \%$ ), $58.2 \%$ in specialty care (IQR $34.8 \%-80.0 \%$ ), $48.6 \%$ in emergency care (IQR 33.7\%-64.5\%) and $63.9 \%$ in mixed types of care (IQR 54.2\%-76.6\%).

The relative impact on categories of services differed across types of care, with a median decline in diagnostic and screening procedures of $66.0 \%$ in specialty care $(\mathrm{n}=158$; IQR $51.0 \%-81.2 \%)$ and $42.2 \%$ in emergency care ( $\mathrm{n}=28$; IQR $35.5 \%-49.4 \%$ ) (figure 3 ). Regarding in-person visits, the largest median decrease was found in specialty care $(64.1 \% \quad(\mathrm{n}=206)$; IQR $38.6 \%-83.1 \%)$, followed by primary care $(61.3 \% \quad(\mathrm{n}=21)$; IQR $22.7 \%-$ $70.6 \%)$ and emergency care $(50.2 \% \quad(\mathrm{n}=283)$; IQR $33.6 \%-65.0 \%$ ). Impact on treatments was similar among types of care. 
Table 1 Characteristics of included articles $(n=517)$

Data source, $\mathrm{n}(\%)$

Administrative health data, single provider

$275(53.2)$

Administrative health data, multiple providers* 99 (19.2)

Survey

$106(20.5)$

Insurance claims data

$8(1.6)$

Other

$29(5.6)$

Provider(s) ${ }^{\star}, \mathrm{n}(\%)$

$\begin{array}{lr}\text { Individual } & 278(53.8) \\ \text { Multiple, local (eg, city, region) } & 87(16.8) \\ \text { Multiple, national } & 112(21.7) \\ \text { Multiple, international } & 40(7.7)\end{array}$

Target population, $\mathrm{n}(\%)$

Adults

72 (13.9)

Children

$72(13.9)$

Children and adults

$102(19.7)$

Not mentioned

$271(52.4)$

COVID-19 period, $\mathrm{n}(\%)$

First semester 2020 (January to June)

$483(93.4)$

First and second semester 2020

$29(5.6)$

Second semester 2020 (July to December)

$4(0.8)$

Not mentioned

$1(0.2)$

Reference period, $\mathrm{n}(\%)$

Dates in 2019 corresponding to the COVID-19 274 (53.0) period

\begin{tabular}{lc} 
Prelockdown period & $110(21.3)$ \\
Other & $36(7.0)$ \\
Not mentioned & $97(18.8)$ \\
Number of measures† by article, mean (SD), & $1.96(1.88)$ \\
range & $1-12$ \\
\hline
\end{tabular}

*Healthcare professional or organisation.

†A measure is a quantitative assessment of the impact of the COVID-19 pandemic on the use of a specific outpatient service.

Paediatric emergency departments appeared to be more impacted (66.7\% median decline in in-person visits; IQR $58.1 \%-76.1 \%)$ than adult or mixed emergency departments (approximately 40\%) (table 3). We observed a similar trend when comparing paediatric $(59.0 \%$ median decrease; IQR 45.2\%-61.6\%) and adult emergency specialty in-person visits $(46.7 \%$ median decrease; IQR $31.5 \%-64.7 \%$ ). In primary care, the reported decreases in in-person visits were more consistent (approximately $60 \%$ ). Overall, the impact on specialties varied widely, ranging from no decline to almost complete interruption. In addition, there were a few cases of an increased volume of in-person visits in adult emergency departments and outpatient practices (general/family medicine, emergency and routine infectious diseases practices, child and adolescent psychiatry).
Table 2 Median relative impact of the COVID-19 pandemic on in-person outpatient care utilisation and number of articles included, by country

\begin{tabular}{|c|c|c|}
\hline Country & Median impact (\%) & Number of articles \\
\hline USA & -56.4 & 106 \\
\hline Italy & -60.3 & 96 \\
\hline International ${ }^{\star}$ & -58.2 & 40 \\
\hline UK & -58.0 & 40 \\
\hline Spain & -77.5 & 24 \\
\hline Turkey & -70.8 & 21 \\
\hline India & -64.9 & 20 \\
\hline Germany & -31.4 & 19 \\
\hline China & -63.9 & 17 \\
\hline France & -59.1 & 11 \\
\hline Brazil & -45.1 & 10 \\
\hline Canada & -55.8 & 9 \\
\hline Singapore & -46.4 & 9 \\
\hline Australia & -32.3 & 8 \\
\hline Ireland & -58.3 & 6 \\
\hline Israel & -32.8 & 6 \\
\hline Japan & -24.0 & 6 \\
\hline Portugal & -51.5 & 6 \\
\hline South Korea & -31.9 & 6 \\
\hline Taiwan & -16.7 & 6 \\
\hline South Africa & -40.4 & 5 \\
\hline Switzerland & -43.5 & 5 \\
\hline Greece & -47.6 & 4 \\
\hline Finland & -21.3 & 3 \\
\hline Argentina & -66.5 & 2 \\
\hline Indonesia & -64.4 & 2 \\
\hline Iraq & -45.0 & 2 \\
\hline Nepal & -55.4 & 2 \\
\hline The Netherlands & -28.7 & 2 \\
\hline Norway & -35.0 & 2 \\
\hline Saudi Arabia & -22.1 & 2 \\
\hline Slovenia & -46.0 & 2 \\
\hline Austria & -71.0 & 1 \\
\hline Belgium & -90.9 & 1 \\
\hline Croatia & -33.9 & 1 \\
\hline Ethiopia & -33.1 & 1 \\
\hline Hungary & -76.9 & 1 \\
\hline Iceland & +16.4 & 1 \\
\hline Iran & -51.1 & 1 \\
\hline Malaysia & -59.8 & 1 \\
\hline Malta & -90.8 & 1 \\
\hline Mexico & -64.7 & 1 \\
\hline Morocco & -29.2 & 1 \\
\hline
\end{tabular}

Continued 


\begin{tabular}{lcc} 
Table 2 & Continued & \\
\hline Country & Median impact (\%) & Number of articles \\
\hline Oman & -70.0 & 1 \\
Pakistan & -45.4 & 1 \\
Peru & -79.7 & 1 \\
Qatar & -40.4 & 1 \\
South Sudan & -10.3 & 1 \\
Thailand & -36.0 & 1 \\
Tunisia & -65.0 & 1 \\
Total & -55.5 & 517 \\
\hline
\end{tabular}

${ }^{*}$ Multiple providers in several countries.

\section{Results from surveys}

The 153/1011 (15.1\%) reported measures not allowing the estimation of a relative impact were usually surveybased $(96.7 \%)$ and mostly related to some type of specialty care $(95.4 \%)$. The most frequently encountered outcome $(86.3 \%)$ was the proportion of survey respondents self-reporting a reduction or interruption (including postponement) in the provision of a specific service. In this subset, the median proportion of respondents self-reporting reduction or interruption of diagnostic and screening procedures was $65.1 \%(\mathrm{n}=31$; IQR $45.0 \%-82.0 \%)$. This proportion was $55.0 \%$ for treatments $(\mathrm{n}=35$; IQR $32.8 \%-74.3 \%)$ and $74.7 \%$ for in-person visits $(\mathrm{n}=66$; IQR $48.7 \%-90.5 \%)$.

\section{DISCUSSION}

This review showed that the COVID-19 pandemic resulted in an almost generalised decline in in-person outpatient care utilisation worldwide, with a $55.5 \%$ overall median relative decrease. However, variability between countries was high and the decrease was less in emergency care than in other types of care (ie, primary and specialty care, screening services). Our findings corroborate those of several reviews that have targeted a similar topic, but in

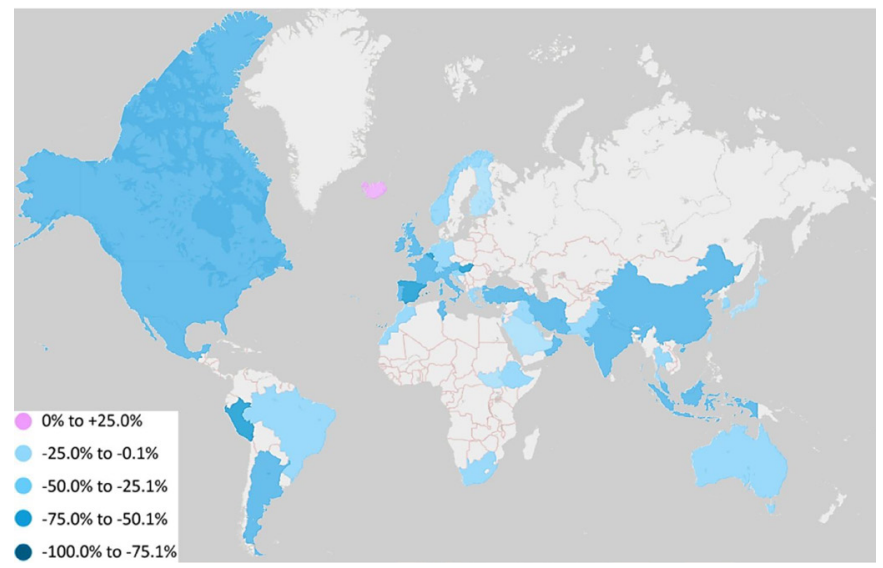

Figure 2 Median relative impact of the COVID-19 pandemic on in-person outpatient care utilisation, by country.

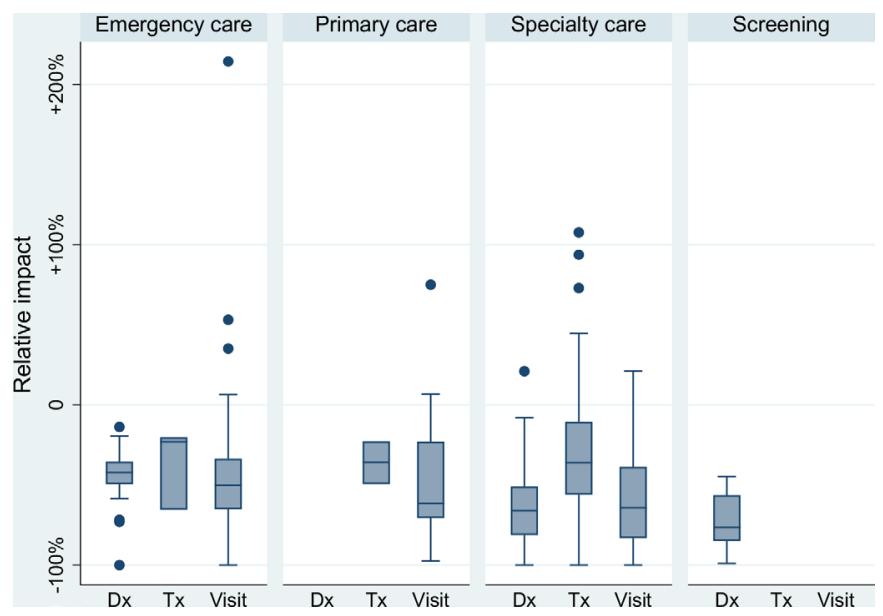

Figure 3 Relative impact of the COVID-19 pandemic on in-person outpatient care utilisation, by type of care and category of service. Dx, diagnostic/screening procedure; Tx, treatment. Whiskers extend to the lowest and highest values within 1.5 times the IQR from the lower and upper quartiles. The dots represent individual values that fall outside this range.

a less comprehensive manner. For example, an international review focusing on orthopaedic services found a $63 \%$ decline in outpatient attendance. ${ }^{6}$ Another review examining the impact of the COVID-19 pandemic on the use of cancer and cardiology services in Italy reached similar conclusions. ${ }^{7}$ Finally, a recent systematic review found smaller median declines $42 \%$ for visits, $31 \%$ for diagnostics and $30 \%$ for therapeutics), but its scope was broader (both outpatient and inpatient services) and the number of articles included $(n=81)$ were lower than in our study. ${ }^{8}$

Differences observed between countries could stem from variable government responses to mitigate the spread of SARS-CoV-2 and face the burden of patients with COVID-19. ${ }^{11}$ Indeed, despite commonalities in state policies, the intensity of containment measures differed across countries in the first months of the pandemic. Heterogeneity of impact could also reflect differences in the resilience of national health systems themselves. ${ }^{12}$ For instance, some countries succeeded better than others in expanding the health workforce, supporting primary and community care and more generally preserving health system functions despite the evolving epidemiological crisis. Of note, the relative increase observed in Iceland is based on a single study and is actually due to an isolated growth in the number of primary care home visits, with in-person office visits showing a concurrent $42 \%$ decrease. $^{13}$

Regarding heterogeneity across types of care, the smaller decline observed in emergency care can be explained by the fact that emergency conditions require, by nature, medical care that cannot be postponed. It can also be explained by the cancellation of elective services in many countries during lockdown. ${ }^{3}$ However, emergency department visits for life-threatening conditions 
Table 3 Relative impact of the COVID-19 pandemic on in-person outpatient visits, by type of care and specialty

\begin{tabular}{|c|c|c|c|c|c|}
\hline & $\begin{array}{l}\text { Median impact } \\
(\%)\end{array}$ & IQR & Minimum & Maximum & $\begin{array}{l}\text { Number of } \\
\text { measures* }\end{array}$ \\
\hline EMERGENCY CARE & -50.20 & {$[-65.0 \%$ to $-33.6 \%]$} & -100.00 & 214.30 & 283 \\
\hline Emergency department visits & -50.90 & {$[-66.3 \%$ to $-36.0 \%]$} & -90.90 & 214.30 & 143 \\
\hline Pediatric & -66.70 & {$[-76.1 \%$ to $-58.1 \%]$} & -90.90 & 1.80 & 57 \\
\hline Unspecified & -42.00 & {$[-50.9 \%$ to $-29.4 \%]$} & -74.30 & -13.90 & 42 \\
\hline Adult and pediatric & -40.20 & {$[-46.9 \%$ to $-30.9 \%]$} & -58.60 & -24.00 & 16 \\
\hline Adult & -38.80 & [-56.9\% to $-30.7 \%]$ & -80.20 & 214.30 & 28 \\
\hline Emergency specialty visits, adult & -46.70 & [-64.7\% to $-31.5 \%]$ & -100.00 & 53.20 & 127 \\
\hline Otorhinolaryngology & -80.80 & {$[-94.4 \%$ to $-62.2 \%]$} & -94.40 & -62.20 & 3 \\
\hline Dermatology & -79.90 & {$[-82.1 \%$ to $-59.1 \%]$} & -82.10 & -59.10 & 3 \\
\hline Ophthalmology & -73.80 & {$[-83.2 \%$ to $-35.3 \%]$} & -95.70 & -25.70 & 6 \\
\hline Maxillofacial and oral surgery & -70.80 & [-71.9\% to $-7.9 \%]$ & -71.90 & -7.90 & 3 \\
\hline Surgery, unspecified & -70.20 & {$[-84.4 \%$ to $-32.2 \%]$} & -88.90 & -24.50 & 5 \\
\hline Hand surgery & -61.70 & {$[-64.0 \%$ to $-52.0 \%]$} & -64.90 & -43.60 & 4 \\
\hline Plastic surgery & -61.50 & {$[-74.5 \%$ to $-43.9 \%]$} & -84.30 & -29.50 & 4 \\
\hline Orthopedics/traumatology & -59.30 & {$[-71.0 \%$ to $-34.3 \%]$} & -79.70 & 3.00 & 24 \\
\hline Neurosurgery & -57.80 & [-84.3\% to $-31.2 \%]$ & -84.30 & -31.20 & 2 \\
\hline Proctology & -56.40 & [-56.4\% to $-56.4 \%]$ & -56.40 & -56.40 & 1 \\
\hline Dental care & -53.20 & {$[-79.4 \%$ to $-27.4 \%]$} & -90.50 & -16.70 & 4 \\
\hline Urology & -51.10 & {$[-57.0 \%$ to $-36.1 \%]$} & -76.90 & -2.70 & 15 \\
\hline Mixed & -50.80 & [-50.8\% to $-50.8 \%]$ & -50.80 & -50.80 & 1 \\
\hline Gastroenterology/hepatology & -43.60 & {$[-58.0 \%$ to $-29.2 \%]$} & -58.00 & -29.20 & 2 \\
\hline Geriatric dental care & -43.50 & {$[-43.5 \%$ to $-43.5 \%]$} & -43.50 & -43.50 & 1 \\
\hline Cardiology & -41.10 & {$[-56.5 \%$ to $-35.4 \%]$} & -56.50 & -35.40 & 3 \\
\hline Vascular surgery & -40.90 & {$[-41.3 \%$ to $-40.5 \%]$} & -41.30 & -40.50 & 2 \\
\hline Psychiatry/mental health & -36.10 & {$[-52.8 \%$ to $-24.1 \%]$} & -100.00 & 6.40 & 26 \\
\hline Gynecology/obstetrics & -35.90 & [-41.1\% to $-34.7 \%]$ & -93.50 & -4.20 & 10 \\
\hline Neurology & -34.40 & [-57.6\% to $-24.6 \%]$ & -57.60 & -24.60 & 3 \\
\hline Oncology/onco-hematology & -33.60 & {$[-33.6 \%$ to $-33.6 \%]$} & -33.60 & -33.60 & 1 \\
\hline Visceral surgery/general surgery & -24.90 & [-24.9\% to $-24.9 \%]$ & -24.90 & -24.90 & 1 \\
\hline Palliative care & -1.90 & {$[-1.9 \%$ to $-1.9 \%]$} & -1.90 & -1.90 & 1 \\
\hline Spine surgery & 4.20 & [4.2\% to $4.2 \%$ ] & 4.20 & 4.20 & 1 \\
\hline Infectious diseases & 53.20 & [53.2\% to $53.2 \%]$ & 53.20 & 53.20 & 1 \\
\hline Emergency specialty visits, pediatric & -59.00 & {$[-61.6 \%$ to $-45.2 \%]$} & -90.20 & 35.30 & 13 \\
\hline Pediatric orthopedics/traumatology & -61.20 & {$[-67.9 \%$ to $-51.1 \%]$} & -90.20 & -37.70 & 9 \\
\hline Pediatric surgery, unspecified & -59.00 & [-59.0\% to $-59.0 \%]$ & -59.00 & -59.00 & 1 \\
\hline $\begin{array}{l}\text { Child and adolescent psychiatry/mental } \\
\text { health }\end{array}$ & -19.40 & [-60.8\% to $35.3 \%]$ & -60.80 & 35.30 & 3 \\
\hline PRIMARY CARE & -61.30 & [-70.6\% to $-22.7 \%]$ & -97.30 & 75.00 & 21 \\
\hline Pediatrics & -64.00 & {$[-69.4 \%$ to $-61.3 \%]$} & -86.80 & -35.50 & 5 \\
\hline General/family practice & -61.20 & [-74.7\% to $-26.5 \%]$ & -86.90 & 75.00 & 12 \\
\hline Other or unspecified & -14.60 & {$[-59.7 \%$ to $-0.2 \%]$} & -97.30 & 6.80 & 4 \\
\hline SPECIALTY CARE & -64.10 & [-83.1\% to $-38.6 \%]$ & -100.00 & 21.00 & 206 \\
\hline Specialty visits, adult & -62.00 & [-82.7\% to $-36.6 \%]$ & -100.00 & 21.00 & 195 \\
\hline Gastroenterology/hepatology & -98.00 & [-98.2\% to $-87.5 \%]$ & -100.00 & -55.50 & 5 \\
\hline Thyroid surgery & -93.30 & {$[-93.3 \%$ to $-93.3 \%]$} & -93.30 & -93.30 & 1 \\
\hline Nephrology & -92.30 & [-92.3\% to $-92.3 \%]$ & -92.30 & -92.30 & 1 \\
\hline Cardiology & -91.80 & {$[-100.0 \%$ to $-67.3 \%]$} & -100.00 & -10.40 & 10 \\
\hline
\end{tabular}


Table 3 Continued

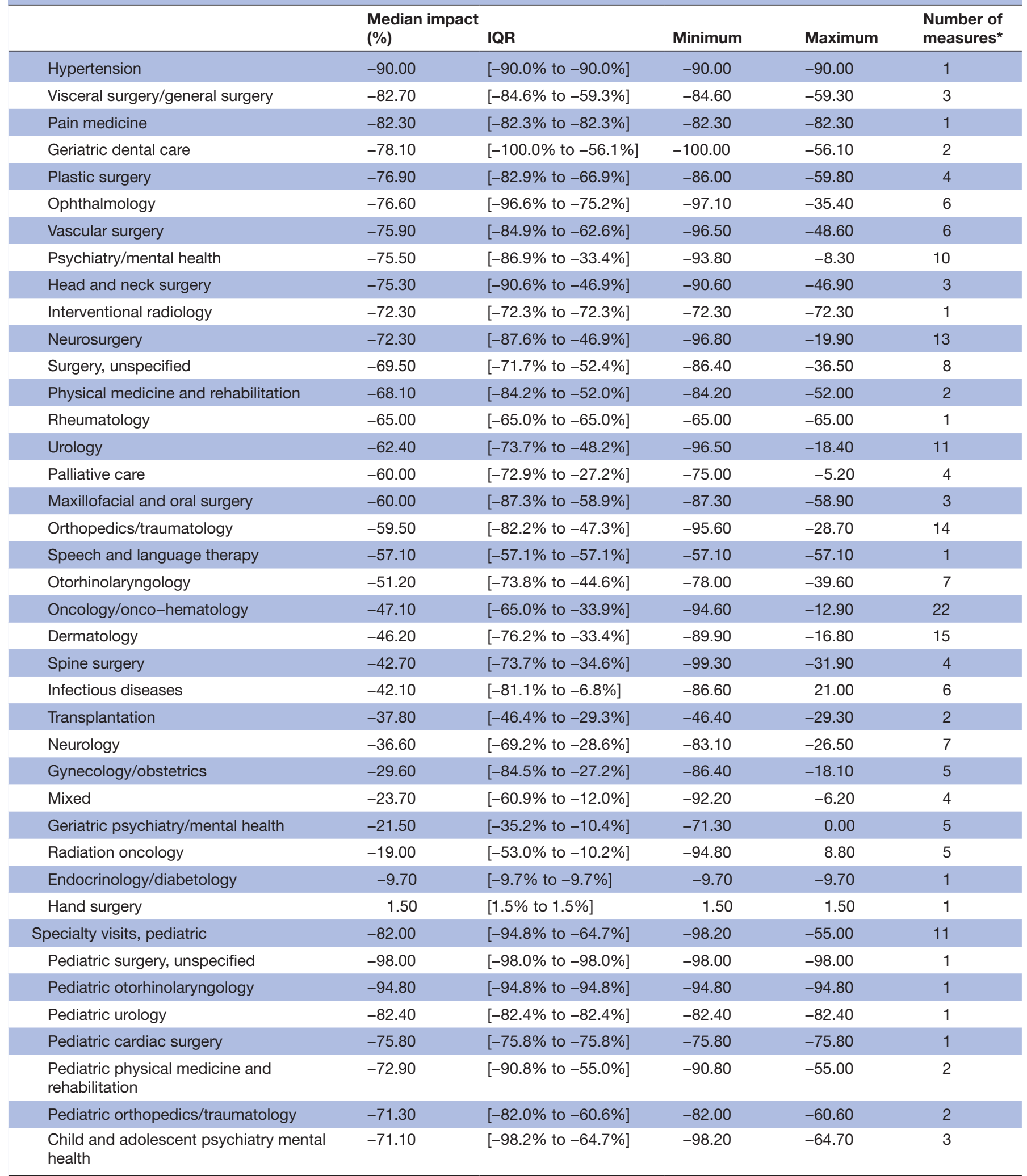

For each subgroup, presented by decreasing order of impact.

bold, uppercase values indicates emergency care, primary care and specialty care

bold, lowercase indicates emergency department visits

${ }^{*}$ A measure is a quantitative assessment of the impact of the COVID-19 pandemic on the use of a specific outpatient service. 
also declined, raising concerns regarding the impact of delayed or non-provided care on patient outcomes. ${ }^{14} 15$ A comparable heterogeneity of impact across medical specialties has been shown by the Commonwealth Fund in the USA, with paediatrics and surgical specialties being the most affected. ${ }^{16}$ Despite being less impacted than in-person visits and diagnostic and screening procedures, the decline observed in treatments, which include cancer therapy and dialysis, for instance, is a very concerning issue regarding patient outcomes. The almost universal suspension of screening services observed is consistent with other research findings and this may lead to delays in diagnosis and future consequences on cancerrelated morbidity and mortality. ${ }^{17}$ Telehealth was used extensively during the COVID-19 pandemic, including in emergency care and specialty medicine, potentially offsetting in-person visits that had to be cancelled or postponed. ${ }^{18-20}$ However, the increase in remote consultations only partially compensated for the decline in face-to-face appointments. ${ }^{21} 22$

The question of the consequences of the non-provision of care resulting from the sanitary crisis remains open. Part of unprovided care may represent care that was not necessary. As suggested by Moynihan et al in July 2020, the 'natural experiment' of the COVID-19 pandemic should be considered as an opportunity both to study the effects of medical care restrictions and to reduce care that might be unnecessary. ${ }^{23}$ Whereas these issues remain to be addressed, the results of our rapid review represent a first step towards a better understanding of this crucial matter.

\section{Limitations}

These results need to be interpreted considering the following limitations. First, a few estimates of the median relative impact of the COVID-19 pandemic were based on a small number of observations (eg, those provided for specific countries or specialties), thus limiting their validity, and there were no data for several countries. Second, most survey-based measures did not allow the estimation of a relative impact and needed to be treated and presented separately. Third, it was not always possible to make a strict distinction between outpatient and inpatient care. Nevertheless, this limitation involves almost exclusively emergency care reports, which did not distinguish outpatients and patients requiring hospitalisation in some instances; moreover, articles explicitly focusing on conditions requiring hospitalisation did not meet our eligibility criteria. Fourth, we did not assess the risk of bias because of the large number of studies included and their nature (ie, mostly short reports with limited methodologic information). Finally, our streamlined process of reference screening could have missed some relevant articles, although we are confident that we captured the vast majority of potential articles during the period considered. Additionally, since we aimed to provide a global picture of the impact of the COVID-19 pandemic on outpatient care utilisation, it seems unlikely that a more exhaustive approach would have drawn very different conclusions.

\section{CONCLUSIONS}

The COVID-19 pandemic has resulted in a major but heterogeneous disruption of in-person outpatient care service delivery worldwide, with largely unknown long-term consequences for population health. Both a thorough assessment of such consequences and the identification of policy instruments to limit this negative impact appear crucial to render health systems more resilient and capable of managing future public health emergencies.

Acknowledgements The authors would like to thank Thomas Brauchli, librarian and literature search specialist at Unisanté, for his skilled support of the literature search, and Rémi Sabonnadière (data scientist) at Unisanté, for his help in the creation of the map.

Contributors Concept and design: JD, M-ALP and IP-B. Acquisition, analysis or interpretation of data: JD, M-ALP and IP-B. Drafting of the manuscript: JD. Critical revision of the manuscript for important intellectual content: JD, M-ALP and IP-B. Statistical analysis: JD. All the authors fulfil all three of the ICMJE criteria for authorship and have agreed to the content of the manuscript in its submitted form. $J D$ is responsible for the overall content as guarantor.

Funding The authors have not declared a specific grant for this research from any funding agency in the public, commercial or not-for-profit sectors.

Map disclaimer The inclusion of any map (including the depiction of any boundaries therein), or of any geographic or locational reference, does not imply the expression of any opinion whatsoever on the part of BMJ concerning the legal status of any country, territory, jurisdiction or area or of its authorities. Any such expression remains solely that of the relevant source and is not endorsed by BMJ. Maps are provided without any warranty of any kind, either express or implied.

Competing interests None declared.

Patient consent for publication Not applicable.

Ethics approval This study does not involve human participants.

Provenance and peer review Not commissioned; externally peer reviewed.

Data availability statement All data relevant to the study are included in the article or uploaded as supplementary information. Extracted data are available in the online supplementary material.

Supplemental material This content has been supplied by the author(s). It has not been vetted by BMJ Publishing Group Limited (BMJ) and may not have been peer-reviewed. Any opinions or recommendations discussed are solely those of the author(s) and are not endorsed by BMJ. BMJ disclaims all liability and responsibility arising from any reliance placed on the content. Where the content includes any translated material, BMJ does not warrant the accuracy and reliability of the translations (including but not limited to local regulations, clinical guidelines, terminology, drug names and drug dosages), and is not responsible for any error and/or omissions arising from translation and adaptation or otherwise.

Open access This is an open access article distributed in accordance with the Creative Commons Attribution Non Commercial (CC BY-NC 4.0) license, which permits others to distribute, remix, adapt, build upon this work non-commercially, and license their derivative works on different terms, provided the original work is properly cited, appropriate credit is given, any changes made indicated, and the use is non-commercial. See: http://creativecommons.org/licenses/by-nc/4.0/.

\section{ORCID iDs}

Julien Dupraz http://orcid.org/0000-0003-0082-8759

Isabelle Peytremann-Bridevaux http://orcid.org/0000-0002-6514-8781

\section{REFERENCES}

1 World Health Organization. Second round of the National pulse survey on continuity of essential health services during the COVID-19 
pandemic: interim report, 2021. Available: https://apps.who.int/iris/ rest/bitstreams/1343409/retrieve [Accessed 24 Jun 2021].

2 Jacobs EA, Ogedegbe O, Fihn SD. Elective care and health services research in the COVID-19 era. JAMA Netw Open 2020;3:e2025731.

3 World Health Organization. Pulse survey on continuity of essential health services during the COVID-19 pandemic: interim report, 2020. Available: https://apps.who.int/iris/rest/bitstreams/1297631/retrieve [Accessed 24 Jun 2021]

4 Riera R, Bagattini Ângela Maria, Pacheco RL, et al. Delays and disruptions in cancer health care due to COVID-19 pandemic: systematic review. JCO Glob Oncol 2021;7:311-23.

5 OECD. Strengthening the frontline: how primary health care helps health systems adapt during the COVID 19 pandemic. OECD policy responses to coronavirus (COVID-19), 2021. Available: https://www. oecd.org/coronavirus/policy-responses/strengthening-the-frontlinehow-primary-health-care-helps-health-systems-adapt-during-thecovid-19-pandemic-9a5ae6da/ [Accessed 24 Jun 2021].

6 Ow ZGW, Cheong CK, Chin YH, et al. A look at the global impact of SARS CoV-2 on orthopedic services. J Clin Orthop Trauma 2021;12:33-9.

7 Di Bidino R, Cicchetti A. Impact of SARS-CoV-2 on provided healthcare. Evidence from the emergency phase in Italy. Front Public Health 2020;8:583583.

8 Moynihan R, Sanders S, Michaleff ZA, et al. Impact of COVID-19 pandemic on utilisation of healthcare services: a systematic review. BMJ Open 2021:11:e045343.

9 Garritty C, Gartlehner G, Nussbaumer-Streit B, et al. Cochrane rapid reviews methods group offers evidence-informed guidance to conduct rapid reviews. J Clin Epidemiol 2021;130:13-22.

10 Moher D, Liberati A, Tetzlaff J, et al. Preferred reporting items for systematic reviews and meta-analyses: the PRISMA statement. BMJ 2009;339:b2535.

11 Hale T, Angrist N, Goldszmidt R, et al. A global panel database of pandemic policies (Oxford COVID-19 government response Tracker). Nat Hum Behav 2021;5:529-38.

12 Haldane V, De Foo C, Abdalla SM, et al. Health systems resilience in managing the COVID-19 pandemic: lessons from 28 countries. Nat Med 2021;27:964-80.
13 Sigurdsson EL, Blondal AB, Jonsson JS, et al. How primary healthcare in Iceland swiftly changed its strategy in response to the COVID-19 pandemic. BMJ Open 2020;10:e043151.

14 Lange SJ, Ritchey MD, Goodman AB, et al. Potential indirect effects of the COVID-19 pandemic on use of emergency departments for acute life-threatening conditions - United States, January-May 2020. MMWR Morb Mortal Wkly Rep 2020;69:795-800.

15 Pines JM, Zocchi MS, Black BS, et al. The effect of the COVID-19 pandemic on emergency department visits for serious cardiovascular conditions. Am J Emerg Med 2021;47:42-51.

16 Mehrotra A, Chernew ME, Linetsky D, et al. The impact of the COVID-19 pandemic on outpatient visits: a rebound emerges, 2020. Available: https://www.commonwealthfund.org/publications/2020/ apr/impact-covid-19-outpatient-visits [Accessed 24 Jun 2021].

17 Alkatout I, Biebl M, Momenimovahed Z, et al. Has COVID-19 affected cancer screening programs? A systematic review. Front Oncol 2021;11:675038.

18 Jaffe TA, Hayden E, Uscher-Pines L, et al. Telehealth use in emergency care during coronavirus disease 2019: a systematic review. J Am Coll Emerg Physicians Open 2021;2:e12443.

19 Loh CH, Chong Tam SY, Oh CC. Teledermatology in the COVID-19 pandemic: a systematic review. JAAD Int 2021;5:54-64.

20 Datta P, Barrett W, Bentzinger M, et al. Ambulatory care for epilepsy via telemedicine during the COVID-19 pandemic. Epilepsy Behav 2021;116:107740.

21 Watt T, Firth Z, Fisher R, et al. Use of primary care during the COVID-19 pandemic, 2020. Available: https://www.health.org.uk/ news-and-comment/charts-and-infographics/use-of-primary-careduring-the-covid-19-pandemic [Accessed 24 Jun 2021].

22 Mehrotra A, Chernew ME, Linetsky D, et al.. The impact of the COVID-19 pandemic on outpatient visits: visits return to prepandemic levels but not for all providers and patients, 2020. Available: https://www.commonwealthfund.org/publications/2020/ oct/impact-covid-19-pandemic-outpatient-care-visits-returnprepandemic-levels [Accessed 20 Dec 2021].

23 Moynihan R, Johansson M, Maybee A, et al. Covid-19: an opportunity to reduce unnecessary healthcare. $B M J$ 2020;370:m2752. 